Journal of

Accident and

Emergency

Medicine 1994

11, 162-165

\title{
Cardiopulmonary resuscitation. Paper 1: a survey of undergraduate training in UK medical schools
}

\author{
C.A.GRAHAM, K.A.GUEST \& D.SCOLLON
}

Faculty of Medicine, University of Glasgow, Glasgow

\section{SUMMARY}

This paper presents the results of a UK national survey of Basic Life Support (BLS) and Advanced Cardiac Life Support (ACLS) training for undergraduate medical students. In all responding medical schools, undergraduates are taught BLS at least once during their course but the assessment and refresher aspects of BLS training are not uniformly covered. There are inconsistencies in ACLS teaching, with some schools providing formal courses, some teaching specific techniques and others providing no ACLS teaching. Most interestingly, of those completing the questionnaire, only $52 \%$ considered present undergraduate training adequate to enable junior house officers to provide an effective resuscitation service. We recommend that all aspects of BLS and ACLS training for medical undergraduates be improved and standardized throughout the UK.

Key words: ACLS, BLS, medical students, resuscitation, training

\section{INTRODUCTION AND METHODS}

Undergraduate medical students, in common with preregistration house officers, ${ }^{1-3}$ MRCP candidates, ${ }^{4}$ consultants $^{5}$ and nursing staff, ${ }^{6}$ have repeatedly been shown to be poor providers of both BLS and ACLS when tested in resuscitation scenarios. Skills in BLS and ACLS depend, to a large extent, on the quality of training and frequency of retraining ${ }^{7}$ but this has been shown to be inadequate and irregular. $^{8}$ Improved training and organization of cardiopulmonary resuscitation (CPR) teaching is facilitated by the appointment of resuscitation training officers. ${ }^{7}$ It was shown some years ago that resuscitation training in UK medical schools was poor and inferior to that provided by North American medical schools. ${ }^{9}$

A postal survey was undertaken of every clinical medical school in the UK to assess the amount of cardiac resuscitation training provided in undergraduate medical schools at the present time. The questionnaire was sent to the Dean of each clinical medical school in the UK who was asked to pass it on to the person whom they considered responsible for organizing training in CPR for medical undergraduates. A copy of the questionnaire is shown in Figure 1.

\section{RESULTS}

Twenty-three valid replies to the 28 surveys we sent out were received, giving a response rate of $82 \%$. The questionnaires were answered by the Dean themselves $(2 / 23,9 \%)$, consultants, professors and senior lecturers $(16 / 23,70 \%)$, resuscitation training officers $(3 / 23,13 \%)$ and others $(2 / 23,9 \%)$. The
Correspondence: C.A. Graham, Medical Student, Flat 6, 60 Lumsden Street, Yorkhill, Glasgow G3 8RH, UK
$\%$ of responding

Topic

UK medical schools

$100(23 / 23)$

Formal Basic Life Support Teaching

$83(19 / 23)$

$57(13 / 23)$

$39(9 / 23)$

$87(20 / 23)$

ACLS Techniques Taught (Not ACLS Course)

Adequate training for undergraduate medical

students to enable them to provide an effective resuscitation service as junior house officers?
Table 1. Results of survey: topics taught during medical courses 
CPR: a survey of training

\section{CARDIOPULMONARY RESUSCITATION TEACHING ENQUIRY FORM}

1. Your Name

2. Your Grade and Speciality

3. Your Medical School

Please circke the appropriate answers

4. Do students in your Medical School formally receive teaching in Basic Life Support (Basic CPR) at any stage in the course?

IF YES: In what year are they taught?

Are there any formal refresher courses?

Are students formally assessed in their ability to perform competent and effective Basic Life support?

IF NO: Do you intend to introduce formal teaching in Basic Life Support in the future?

(if yes, please check and state when)

5. Do students in your Medical School formally receive any teaching in Advanced Cardiac Life Support Techniques (eg intubation, defibrillation, etc)?

IF YES: What techniques are formally taught?

In which year of the course are they taught?

Are students formally assessed in their ability to perform these advanced techniques?

IF NO: Do you intend to introduced formal teaching in these techniques in the future?

(if yes, please check and state when)

6. Does your Medical School run a formal Advanced Cardiac Life Support (ACLS) Course for undergraduate medical students?

IF YES: When was this course introduced?

IF NO: Are there any plans to introduce such a course in your

Medical School in the near future?

YES/NO

123456

YES/NO

YES/NO

YES/NO

YES/NO

123456

YES/NO

YES/NO

YES/NO

YES/NO

7. In your Medical School, which group(s) of doctors is most involved in teaching students Cardiopulmonary Resuscitation?

8. In your opinion, are undergraduate medical students taught enough resuscitation skills to enable them to provide an effective resuscitation service as Junior House Officers?

YES/NO

9. Comments.

Thank you very much for taking the time to complete this form. Please return it to us in the enclosed self-addressed envelope.

Fig. 1. Facsimile of survey questionnaire.

main results are presented in Table 1. Schools were considered to teach ACLS techniques if they taught at least one of the following techniques: defibrillation, endotracheal intubation, central venous cannulation or emergency cardiac drug use. Table 2 details the proportion that different specialities are reported to contribute to the teaching of resuscitation to medical undergraduates.

\section{DISCUSSION}

All the responding medical schools gave formal
BLS teaching tended to be concentrated in the final year of the course, although a significant amount of teaching is also done in the first preclinical year and in the first clinical year of the course. Most medical schools formally assessed students' ability to perform competent BLS, but a much smaller proportion of schools provided a formal BLS refresher course although it has been shown that refresher training is essential for the retention of BLS skills and to maintain competency in the technique. ${ }^{10}$

A total of $87 \%$ of medical schools train their students in various ACLS techniques, the most common being defibrillation and endotracheal 
C.A. Graham et al.

Table 2. Proportion that specialties contribute to teaching of resuscitation

\begin{tabular}{lc}
\hline Speciality & $\begin{array}{c}\text { Contribution to } \\
\text { teaching (\%). }\end{array}$ \\
\hline Anaesthesia & 47 \\
Accident and emergency medicine & 25 \\
General medicine/cardiology & 17 \\
Resuscitation training officers & 11 \\
\hline
\end{tabular}

intubation. Of these schools, $45 \%(9 / 20)$ provide a formal ACLS Course for their students. Of the three schools that do not teach any ACLS techniques formally, one is planning to introduce such teaching and two are not. Of the 14 schools that do not provide a formal ACLS Course, one has plans to start a course, nine have no such plans and four schools did not state their intentions.

ACLS teaching is an excellent learning modality for all medical and paramedical personnel involved in CPR, as well as emphasizing the important concept of effective team work. Given that most medical schools already teach some ACLS techniques to their students, it would be preferable to convert this unstructured teaching into formal ACLS Courses.

Those who completed the questionnaires were also asked if, in their opinion, 'undergraduate medical students were taught enough resuscitation skills to enable them to provide an effective resuscitation service as junior house officers?' Not surprisingly, only $52 \%$ answered 'Yes', with $35 \%$ answering 'No' and $23 \%$ declining to comment. These statistics in themselves illustrate the poor standard of training in cardiac life support that medical students receive.

\section{CONCLUSIONS}

In this study we have demonstrated a wide variety in the standard and amount of resuscitation training for undergraduate medical students in the UK, despite the recommendations of the Royal College of Physicians of London several years ago. ${ }^{11}$ It is well known that improved training leads to an improvement in the standard of resuscitation attempts along with improved chances of survival for the patient. $^{12}$
It is imperative that both BLS and ACLS training for undergraduate medical students is improved, formalized and standardized throughout all UK medical schools.

\section{ACKNOWLEDGEMENTS}

We would like to thank the Deans of the UK medical schools and the consultants, resuscitation training officers and others who kindly completed and returned the questionnaires.

\section{REFERENCES}

1. Casey W.F. (1984) Cardiopulmonary resuscitation: a survey of standards among junior hospital doctors. Journal of the Royal Society of Medicine 77, 921-924.

2. Morris F., Tordoff S.G., Wallis D. \& Skinner D.V. (1991) Cardiopulmonary resuscitation skills of preregistration house officers: five years on. British Medical Journal 302, 626-627.

3. Skinner D.V., Camm A.J. \& Miles S. (1985) Cardiopulmonary resuscitation skills of preregistration house officers. British Medical Journal 290, 1549-1550.

4. David J. \& Prior-Willeard P.F.S. (1993) Resuscitation skills of MRCP candidates. British Medical Journal 306, 1578-1579.

5. Thwaites B.C., Shankar S., Niblett D. \& Saunders J. (1992) Can consultants resuscitate? Journal of the Royal College of Physicians of London 26, 265-267.

6. Wynne G., Martineau T.M., Johnston M., Whiteley C.A. \& Evans T.R. (1987) Inability of trained nurses to perform basic life support. British Medical Journal 294, 1198-1199.

7. Wynne G. (1990) Training and retention of skills. In: T.R. Evans (ed.) $A B C$ of Resuscitation (second edition), pp. 40-44. British Medical Journal, London.

8. Lauder G.R., McQuillan P.J. \& Sear J.W. (1992) Basic life support training. Anaesthesia 47, 1000-1001.

9. Smith G.B. \& Hill S.L. (1987) Resuscitation training for medical students in the United Kingdom - a comparison with the United States of America. Intensive Care Medicine 13, 260-265.

10. Goodwin A.P.L. (1991) Cardiopulmonary resuscitation skills. British Medical Journal 302, 1081-1082.

11. The Royal College of Physicians of London. (1987) Resuscitation from cardiopulmonary arrest. Journal of the Royal College of Physicians of London 21, 1-8.

12. Hanson G.C. (1984) Cardiopulmonary resuscitation: chances of success. British Medical Journal 288, 1324-1325. 